\title{
Splicing fluoride glass and silica optical fibers
}

\author{
Solenn Cozic ${ }^{1, *}$, Simon Boivinet ${ }^{2}$, Christophe Pierre ${ }^{2}$, Johan Boulet $^{2}$, Samuel Poulain ${ }^{1}$ and Marcel Poulain ${ }^{1,3}$ \\ ${ }^{1}$ Le Verre Fluoré, Rue Gabriel Voisin, Campus Kerlann 35170 Bruz, France \\ ${ }^{2}$ Alphanov, Rue François Mitterrand, 33400 Talence, France \\ ${ }^{3}$ Institut Sciences Chimiques de Rennes, Campus Beaulieu, 35042 Rennes Cedex, France
}

\begin{abstract}
Splicing fluoride glass fibers and silica fibers is a critical point for manufacturing all fibered laser modules. As these materials are extremely different, various problems must be considered: thermal, expansion, mechanical, chemical. Reliability and power handling make priority concerns. We report splices made on a 200/220 multimode silica fiber and a double clad 15/250/290 ZBLAN fiber. Splices are proof tested at $300 \mathrm{~g}$ tensile strength. No damage is observed after thermal cycling from $-30{ }^{\circ} \mathrm{C}$ to $85{ }^{\circ} \mathrm{C}$, at $40 \%$ RH during 24 hours. Typical optical splice loss is about $0.2 \mathrm{~dB}$. They withstand $220 \mathrm{~W}$ input power at 976 $\mathrm{nm}$ without any damage and drastic temperature increasing.
\end{abstract}

\section{Introduction}

Fluoride glass fibers are used for the fabrication of various fiber lasers operating in the mid infrared spectrum $(>2 \mu \mathrm{m})$ [1-5] and for supercontinuum generation from 1 to $5 \mu \mathrm{m} \mathrm{[6,7].} \mathrm{The} \mathrm{industrial}$ manufacturing of such laser sources requires splicing silica fibers and fluorides fibers to handle the injection of the pump laser. Thermal splicing has been successfully implemented by several research teams [1, 2, 5]. Reproducibility and reliability of such splices have not been investigated.

This operation raises a number of technical problems in relation to the physical and chemical characteristics of the two materials. A major difference concerns the thermal expansion coefficients: $5.510^{-7} \mathrm{~K}^{-1}$ for $\mathrm{SiO}_{2}$ and $17010^{-7} \mathrm{~K}^{-1}$ for ZBLAN. As a consequence, large mechanical stress will occur at cooling and for any temperature change. Another challenge arises from the steep viscosity change with temperature for fluoride glasses: glass may flow, which leads to the geometric deformation of the fiber. It must be emphasized that the characteristic temperatures of both glasses are extremely different: softening temperature of ZBLAN is below 300 ${ }^{\circ} \mathrm{C}$ while it is above $1000{ }^{\circ} \mathrm{C}$ for vitreous silica. At this temperature fluoride glass decomposes and releases gaseous species. A last problem is the control of the chemical processes at the surface of fluoride fibers. Depending on temperature, silica reacts with fluoride glass melts to produce gaseous silicon tetrafluoride $\mathrm{SiF}_{4}$ according to the chemical equation:

$$
\mathrm{SiO}_{2}+4 \mathrm{~F}^{-}=>\mathrm{SiF}_{4}+2 \mathrm{O}^{=}
$$

Thus temperature appears as a critical parameter. Below glass transition temperature $\mathrm{Tg}$, fiber is in the solid state. Beyond Tg, glass enters the liquid state. It is a necessary condition to create the chemical bonding required for a strong splice. Then the temperature range for which splicing is possible may be narrow.

Insofar as developments focus on high power fiber lasers, one must ensure that pump lasers do not induce damage in fiber core and cladding. Previous experiments have already demonstrated that pump power in excess of $200 \mathrm{~W}$ could be injected in the first cladding of a double clad ZBLAN fiber [3]. Therefore, development of splices handling such high average power is required.

Here, we report the new developments of splices between fluoride glass fibers and silica fibers exhibiting good mechanical and optical performances.

\section{Experimental}

\subsection{Fibers}

The fibers used in this work are: 1) a 200/220 0.22 NA silica fiber from Thorlabs and 2) a 14/250/290 double clad ZBLAN fiber with a second cladding made of low refractive index polymer.

\subsection{Equipment and processing}

The experiments were conducted at ALPHANOV laboratories, using a water cooled, $976 \mathrm{~nm}$ laser diode

- Corresponding author: solenn.cozic@leverrefluore.eu 
from Dilas, pigtailed to a $200 \mu \mathrm{m}$ silica fiber with 0.22 NA, an injection bench with two aspheric lenses, a P1160 thermal camera to monitor the splice temperature, and Ophir air cooled powermeter handling $1.1 \mathrm{~kW}$. After stripping the polymeric coating, fibers were prepared using a LDC401-A Vytran cleaving machine and a GPX3400 Vytran splicing machine. The two fibers set in the splicer and heated to reach the softening temperature of the fluoride glass. Then they were put into contact and the pressure was released while they were slowly cooled. In a last step, the splice was coated with a low refractive index, UV curable resin. 5 splices were made in this way.

\section{Results}

The first measurements have shown that splices could withstand a $450 \mathrm{~g}$ tensile strength. Then a proof test of $300 \mathrm{~g}$ during $30 \mathrm{~s}$ was implemented for the splices used for this study. A splice loss of $0.2 \mathrm{~dB}$ has been measured at $1550 \mathrm{~nm}$. The picture of a typical splice is given in figure 1 . The small difference in fiber diameter may be seen and also the overlap of the fluoride fiber over silica.

Thermal cycling at $40 \% \mathrm{RH}$ was implemented for 24 hours, between $-30{ }^{\circ} \mathrm{C}$ and $85^{\circ} \mathrm{C}$. It does not alter the quality of the splice

Coupling of CW $976 \mathrm{~nm}$ laser diodes in the first fluoride cladding was made at increasing power. No damage occurred on the splice, even at a input power higher than $200 \mathrm{~W}$. The splice temperature has been monitored while the injected average power is increased. At $220 \mathrm{~W}$ input power, the splice temperature is only increased to $40{ }^{\circ} \mathrm{C}$ without any cooling packaging: indeed the splices were only laid on the table. This feature confirms that the splice loss is very low. Note that we injected only $220 \mathrm{~W}$ onto the silica fiber due to no-optimal coupling, leading to a very high temperature increase at the entrance of the silica fiber. This issue could be solved by the splice between the diode output fiber and silica fiber.
Figure 1. Splice of $\mathrm{SiO}_{2}$ and $\mathrm{ZBLAN}$ fibers.

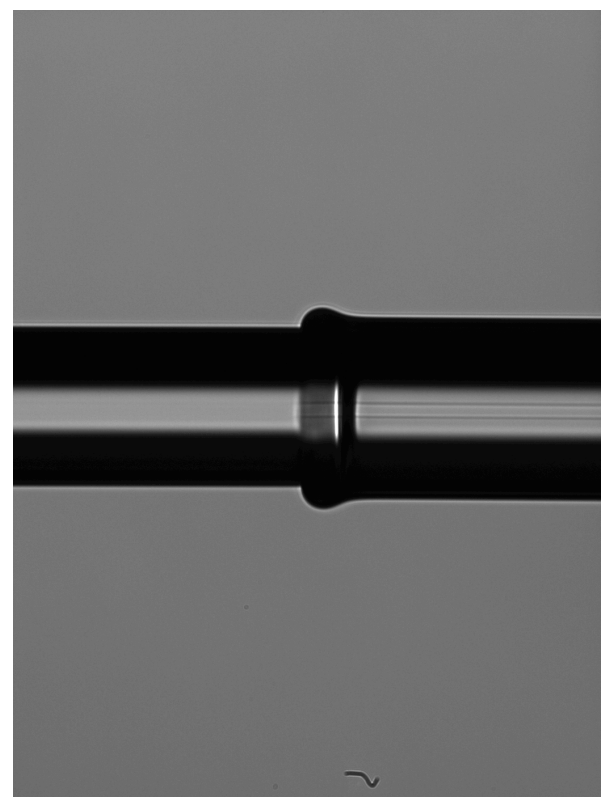

\section{Conclusion}

Silica fibers and fluoride glass fibers were successfully spliced and characterized. These splices withstand significant tensile strength (>300 g), large temperature variations $\left(-30{ }^{\circ} \mathrm{C}\right.$ to $\left.85^{\circ} \mathrm{C}\right)$ during 24 hours, and high power laser of 220 Watts $\mathrm{CW}$ without excessive temperature increase.

These features make possible to manufacture compact, all fibered and reliable high power fiber lasers in the mid-IR.

\section{References}

1. H Okamoto, K. Kasuga, and Y. Kubota, Opt. Lett. 36, 1470 (2011)

2. V. Fortin, M. Bernier, R. Vallée, Opt. Lett, 40, 2882 (2015)

3. Y. O. Aydin, V. Fortin, R. Vallée, M. Bernier, Opt. Lett., 43, 4542 (2018).

4. L. Yang, B. Zhang, D. Jin, T. Wu, X. He, Y. Zhao, J. Hou, Opt. Lett., 43, 5206 (2018).

5. V. Fortin, F. Jobin, M. Larose, M. Bernier, and R. Vallée, Opt. Lett., 44, 491( 2019).

6. J. C. Gauthier, V. Fortin, J. Y. Carrée, S. Poulain, M. Poulain, R. Vallée, M. Bernier, Opt. Lett., 41, 1756 (2016)

7. L. Yang, B. Zhang, D. Jin, T. Wu, X. He, Y. Zhao, and J. Hou, Opt.Lett 43, 5206, (2018) 